\title{
Performance Evaluation of Artificial Intelligence on Soil Property Detection
}

\author{
Smriti Singhatiya \\ P.G. Student \\ Department of Computer Science and Engineering \\ Maharana Pratap College of Technology \\ Gwalior, India \\ singhatiyasmriti@yahoo.com
}

\author{
Dr. Shivnath Ghosh \\ Associate Professor \\ Department of Computer Science and Engineering \\ Maharana Pratap College of Technology \\ Gwalior, India \\ shivghosh.cs@gmail.com
}

\begin{abstract}
Now-a-days there is a need to study the nutrient status in lower horizons of the soil. Soil testing has played historical role in evaluating soil fertility maintenance and in sustainable agriculture. Soil testing shall also play its crucial role in precision agriculture. At present there is a need to develop basic inventory as per soil test basis and necessary information has to be built into the system for translating the results of soil test to achieve the crop production goal in new era. To achieve this goal artificial intelligence approach is used for predicting the soil properties. In this paper for analysing these properties support vector regression (SVR), ensembled regression (ER) and neural network (NN) are used. The performance is evaluated with respect to MSE and RMSE and it is observed that ER outperforms better with respect to SVR and NN.
\end{abstract}

Keywords: Yield Prediction, Data Mining, Soil Analysis, SVR, NN, ER, MSE, RMSE.

\section{INTRODUCTION}

Horticulture depends to a large extent on the quality of the soil, but in the long run, the increase in agricultural production will result in loss of soil. It is necessary to recognize the methods that repress this elimination of supplements and, moreover, restore the necessary supplements in the soil, thus continuing to receive high quality and large-scale plant productions [1]. In horticulture, soil welfare means that soil can force physical, composite and organic practices for reliable profitability with high yields. The great nature of the soil guarantees us the maintenance and the arrival of water and supplements, the improvement and the continuous development of the roots, while maintaining the biotic state that gives normal results and combats rotting [2].

Soil is very important for plant life. It consists of solids (minerals and organic matter), liquids (water and solutes) and gases (mainly oxygen and carbon dioxide) and contains living organisms. All these elements provide their physical and chemical properties. To maintain fertility, achieve better yield and protect the environment, it is necessary to nurture the soil properly. On the other hand, soil tests are essential to manage it properly. A soil test is the study of a soil sample to discover an additional substance, its composition and various attributes. As a general rule, soil tests are performed to determine the wealth and indicate the gaps to be corrected [3]. The analysis of soil nutrients is very useful for the farmer in determining the type of yield to be grown in a particular soil condition.

Soil fertility, which refers to the intrinsic capacity of the soil to provide essential nutrients to plants in sufficient and adequate proportions for optimal growth, is one of the key elements for determining soil productivity. The management of Indian soil fertility requires sustainable high-level production to produce adequate food for the growing population. Good soil fertility management requires careful identification of the limits of current nutritional deficiencies and monitoring of changes in soil fertility to predict their shortage [4]. These gaps must be mitigated by sound and best practices in terms of nutrients, water, plants and energy for soil management, in order to maintain food production at a reasonable level to ensure high productivity at the same time. future. Therefore, managing soil fertility at optimal levels is one of the key factors for achieving high and sustainable productivity $[5,6]$

Soil fertility is one of the most important factors in crop control. The macronutrients $(\mathrm{N}, \mathrm{P}, \mathrm{K})$ and the micronutrients $(\mathrm{Zn}, \mathrm{Cu}, \mathrm{Fe}$ and $\mathrm{Mn})$ are important soil components that control their fertility. The characterization of soil in relation to the assessment of the fertility status of an area or region is important in the context of sustainable agricultural production. Due to the unbalanced and inadequate use of fertilizers and the low efficiency of other inputs, the efficiency of the reaction (production) of chemical fertilizers has significantly decreased in recent years with intensive cultivation. Fluctuations in nutrient intake are a natural phenomenon and some of them may be sufficient while others are inadequate [6].

In this work, data mining classification methods are used to study soil nutrients. Data mining involves extracting information from a data set and transforming it into a structure that is understandable for future use. Various data collection methods are available for the field 
DOI: https://doi.org/10.24113/ijoscience.v5i7.166

research sector. Classification is one of the data mining techniques that automatically create a model of classes from a set of records that contains class labels. Popular classification techniques include decision trees, neural networks, k-nearest neighbour, SVM, and Naïve Bayesian classifier etc.

\section{ANALYSIS OF SOIL}

Soils are formed by the combination of weathered rock materials with humus. We also know that soils supplies water and nutrients to flora. Soils also protect and purify rain water, pests and wildlife habitation. A little bit of hydroponics (soilless agriculture) are developed throughout the globe, but still their percentage is only 10.6 of total soils under conservation. The country prosperity is depending upon soils of that country.

Soil analysis and their classification is very critical because in the entire globe the types of the soils are same, but their analysis results may vary from location to location depending on various characteristics of soils. When analyzing the soils, we should consider the fundamental substantial, organic and compound properties of soils. The classification of soils deals with the methodical cataloging of soils depends on their individual characteristics, as well as decisive factor that dictate choice in use. Classification of Soils is one of the challenging areas in data mining and machine learning, In classification of soils can be started from the viewpoint of soils as a matter and soil as a resource.

The following are various types of soils in India.

\section{A. Alluvial Soils}

These soils are produced by the deposition of sediments carried by rivers. These soils are highly loaded with humus and very much productive. They are found in Great Northern plain, lower valleys of Narmada and Tapti and Northern Gujarat. These soils are transformed year by year.

\section{B. Black Soils}

The basic material of black soils volcanic rocks and lavaflow. These soils are spread over Deccan Lava Tract which includes parts of Maharashtra, Chhattisgarh, Madhya Pradesh, Gujarat, Andhra Pradesh and Tamil Nadu. These soils have huge amount of clay, it may be more than $62 \%$. These soils have chemical composition of alumina, iron oxide, magnesium carbonates and lime and also Potash but are short of in Phosphorus, Nitrogen and Organic matter.

\section{Red Soils}

The color of these soils is due to heavy presentation of iron oxide. Acidic content in these soils are high, and phosphates and nitrogen is less. These soils are unable to retain moisture and water. These soils are formed due to slow breaking of metamorphic rocks and crystalline. They spread over the whole of Tamil Nadu, Andhra
Pradesh, Chhattisgarh, Karnataka, Maharashtra and parts of Orissa.

\section{Literate Soils}

These soils are formed where heavy temperatures and heavy rainfalls occurred alternatively, normally these soils are final creation of weather. These soils contain good composition of bauxite or ferric oxides and less composition of potash and nitrogen. These are spread around in Kerala, Tamil Nadu, Maharashtra, Chhattisgarh and hilly areas of Orissa and Assam.

\section{E. Mountain Soils}

These soils are formed at hill slopes by gathering of organic matter derived from forest and woodlands. They are found in Himalayan region and also appeared in other regions according to altitude. These soils characteristics are based on climate, ground configuration and on parent rocks.

\section{F. Desert Soils}

In the desert regions of Rajasthan, soils are not well developed. As evaporation is in excess of rainfall, the soil has a high salt, alkaline content. These soils are naturally sandy and have less organic matter.

\section{RELATED WORK}

In the field of agriculture, several jobs have been done using data mining techniques. According to the research article [7], the researcher accepts the challenge of transforming raw data into useful information. A large amount of data is collected and stored for analysis with sensors and a GPS. This information is used with the neural network for the prediction of grain yield.

Dr. Ramesh [11] has proposed data models that provide great accuracy and generality in terms of performance prediction capabilities. The work to predict yield is done by analyzing the annual precipitation, using KNN, ANN and SVM for this purpose. Data mining techniques are also used in the field of land.

Shweta Taneja [8] worked to identify useful relationships between different soil types. Here, the grouping technique with the WEKA tool has been implemented to create clusters of soil based on their salinity.

P.Bhargavi [5] proposed data mining techniques, when applied to an agricultural soil profile, may improve the verification of valid soil profile classification. The researcher used Naive Bayes classification technique for the classification of the soil. Many researchers have suggested various yield prediction and classification techniques for crops or soil, but a little prominence is given to do it by analysing nutrients and micronutrients content in soil.

To the best of our knowledge Gideon O Adeoye [12] to his knowledge, focused on the physical factors of the soil, the nutrient content available in the soil and the content of the ear corn leaves. Regression equations were obtained 
DOI: https://doi.org/10.24113/ijoscience.v5i7.166

for each of the soil factors and the plant to predict yield, which predicts yield with the levels of each factor in all soils, all other constant factors.

The nutrient content of the leaves on yield was also studied by D. Almaliotis [13]. Referring to the work discussed above, this manuscript presents the analysis and classification of soils in terms of nutrients and micronutrients, and to predict crops.

Moni Paul et al. [14] describes a system that uses data mining techniques to predict the category of soil data records analyzed. The category of crop yields expected show. The crop yield prediction problem is formalized as a classification rule, in which the nearest Bayes and $\mathrm{K}$ Nearest Neighbour methods are used.

\section{Performance Evaluation of Artificial INTELLIGENCE APPROACHES}

\section{A. Soil Properties}

Global Position System (GPS) based one hundred Twenty five surface soil $(0-15 \mathrm{~cm})$ samples were collected from five blocks (Mungaoli, Chanderi, Ishagarh, Ashoknagar and Sadora) of Ashoknagar district during April to May 2016 and were analysis for their mechanical, physical, chemical characteristics and status of different available nutrient (N, P, K, S, Zn, Cu, Mn and $\mathrm{Fe}$ ).

Soil Properties that are determined in this paper are discussed below:

\section{Soil Ph}

Soil $\mathrm{pH}$ of studied area was found in the range of $7.2-8.6$ under different villages with the average value of 8.0. Maximum average value of soil $\mathrm{pH}$ (8.1) was observed in Ashoknagar block whereas minimum value (7.9) noted in Sadora block of Ashoknagar district. Higher $\mathrm{pH}(>8.5)$ in some of the samples indicate towards the fact that the soils are infested with alkalinity.

\section{Electrical conductivity}

In the present study conductivity values for five blocks of Ashoknagar district ranges from 0.32 to $0.62 \mathrm{~d} \mathrm{~S} \mathrm{~m}^{-1}$ with the average value of $0.45 \mathrm{~d} \mathrm{~S} \mathrm{~m}^{-1}$. It showed a considerable variation with type of topography of soils. All the soil samples were found to be normal (EC $<1.0$ $\mathrm{dSm}^{-1}$ ) category. The normal EC may be ascribed to leaching of salts to lower horizons.

\section{Organic carbon}

Status of organic carbon under studied area was in the range of $2.14-7.15 \mathrm{~g} \mathrm{~kg}^{-1}$ of under different villages with the average value of $4.42 \mathrm{~g} \mathrm{~kg}^{-1}$. Maximum average organic carbon content $\left(4.74 \mathrm{~g} \mathrm{~kg}^{-1}\right)$ was obtained in Isagarh whereas minimum value (3.94 $\mathrm{g} \mathrm{kg}^{-1}$ ) in Mungaoli block of Ashoknagar district.
The low organic carbon content in these soils may be attributed to the poor vegetation and high rate of organic matter decomposition under hyperthermic temperature regime which leads to extremely high oxidizing condition. Removal of the surface soils containing high organic carbon due to erosion was responsible for the lower organic carbon.

\section{Calcium carbonate}

Calcium carbonate content in the surface soil samples of different blocks of Ashoknagar district was distributed in varied from 0.5 to $3.5 \%$ with an mean value of $1.8 \%$, In semi-arid regions, since rainfall is less as compared to annual evapo-transpiration, less water in available for the leaching of insoluble carbonates and bicarbonates of calcium.

\section{B. Performance Evaluation}

The relationship between available nutrients with different soil properties were performed using different artificial intelligence algorithm such as support vector regression (SVR), ensembled regression (ER) and neural network $(\mathrm{NN})$. The performance measures are discussed below:

\section{Mean Square Error (MSE)}

MSE of any estimator (classifier) measures the average squares of errors or deviations, i,e. the difference between the estimator and what is estimated. MSE is a risk function corresponding to the expected value of the squared error loss.

$$
M S E=\frac{1}{N}\left(\text { Target }_{\text {value }}-\text { Obtained }_{\text {value }}\right)
$$

Root Mean Square Error (RMSE)

RMSE is a parameter that determines the difference in squares between the output and the input.

$$
R M S E=\sqrt{M S E}
$$

Table 1: MSE Comparison of SVM, NN and ER

\begin{tabular}{|c|c|c|c|}
\hline $\begin{array}{c}\text { Soil } \\
\text { Properties }\end{array}$ & RF & NN & SVM \\
\hline Soil Ph & 0.100102 & 0.191042 & 0.34641 \\
\hline $\begin{array}{c}\text { Electrical } \\
\text { Conductivity }\end{array}$ & 0.020249 & 0.08308 & 0.34641 \\
\hline $\begin{array}{c}\text { Organic } \\
\text { Carbons }\end{array}$ & 0.32024 & 4.008173 & 0.34641 \\
\hline $\begin{array}{c}\text { Calcium } \\
\text { Carbonate }\end{array}$ & 0.180819 & 1.044836 & 0.34641 \\
\hline
\end{tabular}


DOI: https://doi.org/10.24113/ijoscience.v5i7.166

Table 1: RMSE Comparison of SVM, NN and ER

\begin{tabular}{|c|c|c|c|}
\hline $\begin{array}{c}\text { Soil } \\
\text { Properties }\end{array}$ & RF & NN & SVM \\
\hline Soil Ph & 0.01002 & 0.036497 & 0.12 \\
\hline $\begin{array}{c}\text { Electrical } \\
\text { Conductivity }\end{array}$ & 0.00041 & 0.006902 & 0.12 \\
\hline $\begin{array}{c}\text { Organic } \\
\text { Carbons }\end{array}$ & 0.102553 & 2.06545 & 0.12 \\
\hline $\begin{array}{c}\text { Calcium } \\
\text { Carbonate }\end{array}$ & 0.032696 & 1.091683 & 0.12 \\
\hline
\end{tabular}

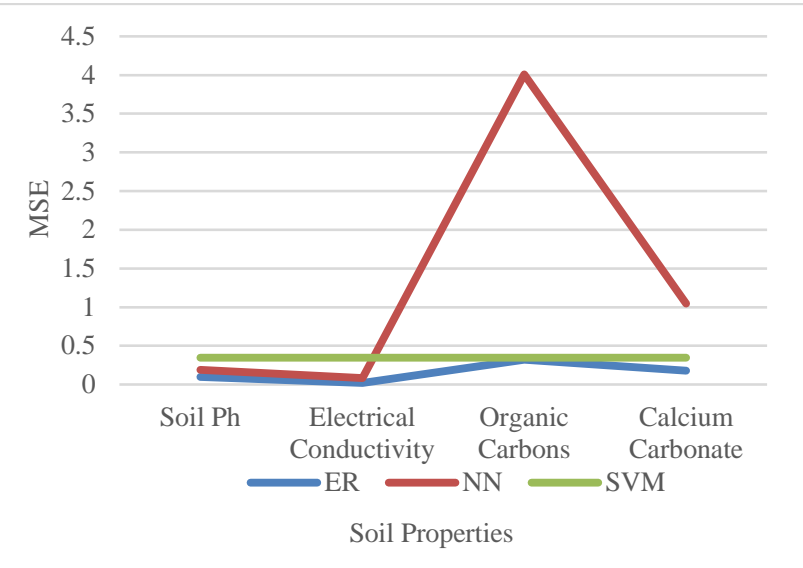

Figure 1: MSE Evaluation for Soil Properties Prediction

Figure 1 and table 1 represents the MSE performance evaluation of Ensemble regression, support vector machine and neural network. From figure it has been analysed that for forecasting 4 different soil properties, ensemble regression technique forecast with minimum error. So, if the research work is proceeded with ER technique the it would provide efficient results.

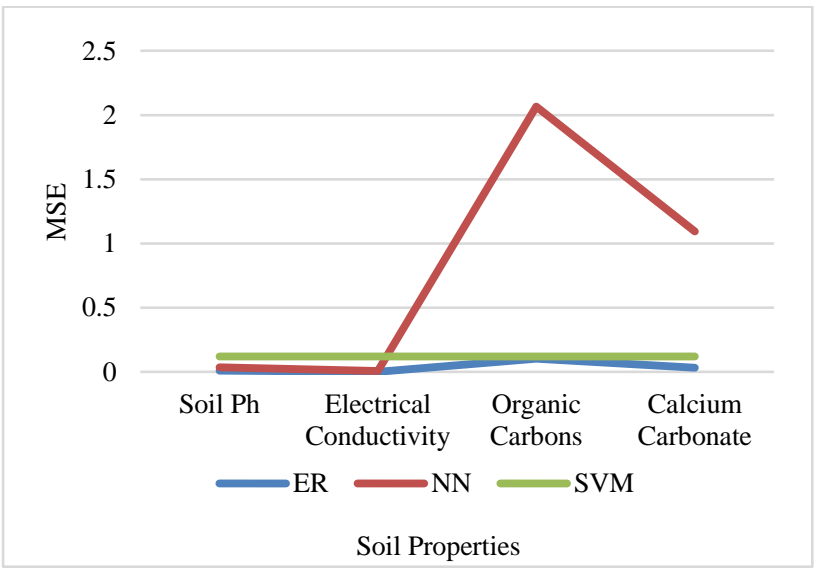

Figure 2: RMSE Evaluation for Soil Properties Prediction

Figure 2 and table 2 represents the RMSE performance evaluation of Ensemble regression, support vector machine and neural network. From figure it has been analysed that for forecasting 4 different soil properties, ensemble regression technique forecast with minimum error as compared to other two artificial intelligence techniques.

\section{Conclusion}

In this paper, classification of different soil properties are performed by applying artificial intelligence approach. Four different soil properties are analysed such as soil ph value, calcium carbonate, organic carbon and electricity conductivity. For analysing these properties support vector regression (SVR), ensembled regression (ER) and neural network (NN) are used. From result analysis it has been concluded that ensembled regression technique outperforms better with respect to mean square error (MSE) and root mean square error (RMSE).

\section{REFERENCES}

[1] Mucherino, P. Papajorgji, P.M. Pardalos, "Data Mining in Agriculture", Springer, 2009.

[2] Mucherino, Petraq Papajorgji, P. M. Pardalos," A survey of data mining techniques applied to agriculture", 25 May 2009 SpringerVerlag 2009.

[3] Sally Jo Cunningham and Geoffrey Holmes,'Developing innovative applications in agriculture using data mining", Department of Computer Science, University of Waikato Hamilton, New Zealand.

[4] Cover TM, Hart PE," K Nearest Neighbor pattern classification", IEEE Trans Info Theory 13(1): 21-27, 1967.

[5] P.Bhargavi, Dr.S.Jyothi, "Applying Naive Bayes Data Mining Technique for Classification of Agricultural Land Soils", IJCSNS International Journal of Computer Science and Network Security, VOL.9 No.8, August 2009.

[6] Dr. Shivnath Ghosh, S. S. (2018). A Review on Soil Property Detection using Machine Learning Approach. SMART MOVES JOURNAL IJOSCIENCE, 4(8), 6 . https://doi.org/10.24113/ijoscience.v4i8.152.

[7] Georg Rub, Rudolf Kruse, Martin Schneider and Peter Wagner, "Data Mining with Neural Networks for Wheat Yield Prediction".

[8] Shweta Taneja, Rashmi Arora, Savneet Kaur, "Mining of Soil Data Using Unsupervised Learning Technique", International Journal of Applied Engineering Research, ISSN 0973-4562 Vol. 7 No.11, 2012.

[9] M. C. S. Geetha," Implementation of Association Rule Mining for different soil types in Agriculture", International Journal of Advanced Research in Computer and Communication Engineering Vol. 4, Issue 4, April 2015.

[10] M. Soundarya, R. Balakrishnan," Survey on Classification Techniques in Data mining”, International Journal of Advanced Research in Computer and Communication Engineering Vol. 3, Issue 7, July 2014.

[11] D Ramesh, B Vishnu Vardhan, "Data mining Techniqued and applications to agriculture yield data", International Journal of Advanced Research in Computer and Communication Engineering Vol. 2, Issue 9, September 2013.

[12] Gideon O Adeoye, Akinola A Agboola, "Critical levels for soil $\mathrm{pH}$, available $\mathrm{P}, \mathrm{K}, \mathrm{Zn}$ and $\mathrm{Mn}$ and maize ear-leaf content of $\mathrm{P}, \mathrm{Cu}$ and $\mathrm{Mn}$ in sedimentary soils of South Western Nigeria", Nutrient Cycling in Agroecosystems, Volume 6, Issue 1, pp 65-71, February 1985.

[13] D. Almaliotis, D. Velemis, S. Bladenopoulou, N. Karapetsas, "Appricot yield in relation to leaf nutrient levels in Northern Greece", ISHS Acta Horticulturae 701: XII International Symposium on Apricot Culture and Decline.

[14] Monali Paul, Santosh K. Vishwakarma, Ashok Verma, "Analysis of Soil Behaviour and Prediction of Crop Yield using Data Mining Approach", International Conference on Computational Intelligence and Communication Networks, 2015. 